\title{
Regional innovation systems: what can we learn from 25 years of scientific achievements?
}

Cristina Fernandes , Luís Farinha , João J. Ferreira , Björn Asheim \& Roel Rutten

To cite this article: Cristina Fernandes, Luís Farinha, João J. Ferreira, Björn Asheim \& Roel Rutten (2020): Regional innovation systems: what can we learn from 25 years of scientific achievements?, Regional Studies, DOI: 10.1080/00343404.2020.1782878

To link to this article: https://doi.org/10.1080/00343404.2020.1782878

曲 Published online: 30 Jul 2020.

Submit your article to this journal ¿

Џll Article views: 403

Q View related articles $ک$

View Crossmark data 


\title{
Regional innovation systems: what can we learn from 25 years of scientific achievements?
}

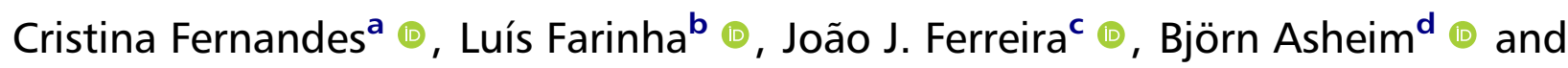 \\ Roel Rutten ${ }^{\mathbf{e}}$
}

\begin{abstract}
The regional innovation systems (RIS) concept has become popular among academics, political decision-makers and regional stakeholders of innovation. Understanding the competitive dynamics of RIS and their impact on regional competitiveness today has thus become a priority. This paper provides researchers, academics, political decision-makers and other interested parties with a map of the different approaches to RIS, aiding in the definition of new territorial innovation policies. With a co-citation resource approach, an extensive search of the Web of Science database was carried out and it encountered four clusters in the literature on RIS: regional knowledge systems; regional institutional systems; regional research and development systems; and regional network systems. This correspondingly sets out new theoretical perspectives based on bibliometric analysis techniques and new paths for scientific reflection and research.
\end{abstract}

KEYWORD

regional innovation systems; regional development; innovation; innovation policy; entrepreneurship

JEL M20, O30

HISTORY Received 5 June 2019; in revised form 12 May 2020

\section{INTRODUCTION}

Edquist (1997) defines innovation systems as complexity of elements or components that work together mutually condition and contract other complexes, each element having well-defined functions. For Lundvall (1992) an innovation system is constituted by elements and relations that interact in the production, diffusion and use of the new economic knowledge.

The concept of regional innovation systems (RIS) has surged in popularity among academics and transversally across different disciplinary fields, with political influence at the global scale. In his article published in the Technology in Society journal, Doloreux (2002) seeks to help readers provide answers to the question just what should we know about regional innovation systems?'. In the same issue, Chung (2002) argues that the concept represents a good instrument for efficiently and effectively managing national innovation systems given that this approach may nurture different sector-based innovation systems in different regions.

According to Rinkinen et al. (2016), the objective of modern innovation policies encapsulates the strengthening of the innovation capacities of regions, their organizations and people. Moulaert and Sekia (2003) argue that following the logic of the growth pole model, it is expected that the infrastructure work combined with a significant investment aid manage the production initiatives necessary in lagging regions. In turn, Zhao et al. (2015) maintain that regional level collaboration between organizations is

\section{CONTACT}

a (Corresponding author) cristina.isabel.fernandes@ubi.pt

University of Beira Interior, Department of Management and Economics, Covilhã, Portugal; NECE - Research Unit in Business Sciences, Covilhã, Portugal; and Centre for Corporate Entrepreneurship and Innovation at Loughborough University, Loughborough, UK.

${ }^{\mathbf{b}}$ luis.farinha@ipcb.pt

Polytechnic Institute of Castelo Branco, Castelo Branco, Portugal; and NECE - Research Unit in Business Sciences, Covilhã, Portugal.

‘]jimf@ubi.pt

University of Beira Interior, Department of Management and Economics, Covilhã, Portugal; and NECE - Research Unit in Business Sciences, Covilhã, Portugal.

d@Bjorn.T.Asheim@uis.no

UiS Business School/Centre for Innovation Research, University of Stavanger, Stavanger, Norway.

e@r.p.j.h.rutten@uvt.nl

Tilburg University, Tilburg, the Netherlands; European Regional Affairs Consultants (ERAC); and Newcastle Business School, Northumbria University, UK. 
divided into the following categories: (1) public versus private organizational mentalities; (2) public versus private resources; (3) capacity for innovation versus the infrastructures available; (4) innovation (resources allocated) versus production of innovation; (5) production of knowledge versus dissemination of knowledge; and (6) collaborative capacities versus productive capacities. Asheim and Coenen (2005) add that the analysis of the competitive dynamics of RIS should take into consideration the specific context of application, including the characteristics of the local business environment as well as the innovation processes and their respective bases of knowledge. However, in the perspective of Andersson (2013), RIS emerge as weak alliances between private and public interests, government institutions, companies and other organizations, even while they may foster increases in regional competitiveness and productivity.

Various partnerships constitute key components of RIS, including the fields of research and development (R\&D). Financial support from governments in the initial $\mathrm{R} \& \mathrm{D}$ investment phase and for upstream companies in general raises the likelihood of success of innovative initiatives as well as strengthening collaborative $\mathrm{R} \& \mathrm{D}$ projects, especially between companies and universities (Lee \& Park, 2006).

From the perspective of academic entrepreneurship and the third mission of universities (their involvement with the regional community), as a dimension acting within the scope of the RIS dynamics, the number of companies located close to a university is positively influenced by both the region's capacity for knowledge and the university's ability to produce knowledge (Audretsch \& Lehmann, 2005; Predazzi, 2012).

Hence, from an innovation system-based regional competition perspective, there is a fundamental need to thoroughly understand what lies beyond the obvious in terms of defining innovation policies. This requires the historical contextualization of these approaches as well as the different research positionings on these issues.

Bibliometric analysis is currently the methodology most widely applied in order to evaluate already existing research results (Mutschke et al., 2011), applying quantitative and statistical analysis to publications, their articles and their respective citations. This serves for the evaluation of the research performance given the procedures return data on all of the activities ongoing in a particular scientific field and the summaries of this data open up a broad perspective on the activities and impacts of research, especially the respective researchers, journals, universities and countries (Hawkins, 1977; Osareh, 1996; Thomsom Reuters, 2008).

The objective of this study includes providing researchers focused on RIS with a chart that enables a better understanding of the publications interrelated with this theme as well as how they evolved over time. To this end, it applies a combination of bibliometric techniques such as citations, co-citations and social network analysis to study the scientific field surrounding RIS.
The paper is structured as follows. The next section gives a literature review. The third section describes the methodology and data. The fourth section gives the results. The fifth section concludes.

\section{LITERATURE REVIEW}

RIS (Asheim et al., 2019; Asheim \& Gertler, 2005; Cooke, 1992) contain dynamic strategic alliances between private and public actors, including the decision-makers in political institutions, companies and other organizations (Andersson, 2013).

Rondé and Hussler (2005) propose that the literature on RIS conceives of innovation as an evolutionary and social process of collective learning. Nevertheless, their study also raises some questions associated with the performances of sector-based systems in contrast with the performances of RIS as a whole.

According to Moulaert and Sekia (2003), there are different views of innovation in territorial innovation models (TIM): (1) the innovative milieu, where the core innovation dynamics is based on capacity of firms to innovate through the relationships with other agents of the same milieu; (2) industrial district, based on the capacity of actors to implement innovation in a system of common values; (3) RIS, innovation as an interactive, cumulative and specific process of R\&D; (4) new industrial spaces, focused on a result of R\&D and its implementation and the application of new production methods; (5) local production systems-based innovation dynamics; and (6) learning regions, close to RIS, but stressing co-evolution of technology and institutions.

Cooke et al. (1997) clarify how strengthening the regional capacities directly contributes towards fostering systemic learning as well as boosting the performance of interactive innovation. Within the same framework, Chung (2002) highlights how the RIS concept proves a useful instrument for efficiently managing national innovation systems given that this may lead to the effective management of specific systems focusing on sector-based innovations in different regions.

Many questions have been asked about how geographical proximity should be conceptualized in the study of regional innovation. In the vision of Shearmur (2010) it is determinant to understand space as a continuous field of opportunities, with accessibility to factors of innovation that play a fundamental role for local innovation. For Hassink and Klaerding (2012) came the end of the learning region as we knew it, associated with learning processes in space and the development of regional studies; they highlighted now the processes of learning are influenced by the culture in the relationships or networks of people and organizations.

In Europe, a new approach to innovation policies is currently undergoing implementation. Countries are structuring tenders around the development of innovation networks (Eickelpasch \& Fritsch, 2005). 
In China, Zhao et al. (2015), in their study approaching innovation and regional collaboration, and applied to 30 Chinese regions, conclude that the main implications of their analysis include the need for a better utilization of the resources available (inputs), a better focus on generating research and innovation results (outputs), furthermore highlighting the importance of reinforcing the organizational mentality (culture), with a view to the continuous development and improvement of regional innovation capacities.

Asheim and Coenen (2005) identify the existence of different types of RIS based upon two different contexts producing the necessary base of knowledge: (1) an analytical knowledge base; and (2) a synthetic knowledge base. These types respectively convey different mixtures of tacit and codified knowledge, qualifications and competences, the companies and organizations involved as well as the specific challenges in terms of the competitiveness of a globalized economy in which support for innovation proves fundamental. The existence of regional systems of innovation leveraged on analytical knowledge bases normally emerge in science-based industries (e.g., information technology, biotechnology). The traditional constellation of industrial clusters, served by innovation support entities and that establish the RIS framework, normally stem from the surrounding industries and a synthetic knowledge base (e.g., engineering-based industries).

The current priority objectives for innovation policies encapsulate deepening the capacity for the innovation of regions, their organizations and their human capital, also including the participation of social companies and their respective focus on social sustainability (Rinkinen et al., 2016). The role of entrepreneurship arising out of universities has come into focus in recent decades and furthermore highlight its positive contribution towards the development of regions (D'Este \& Patel, 2007; Etzkowitz \& Leydesdorff, 2000; Leuven, 2003).

A broader vision, which reaches beyond the innovation role of 'entrepreneurial universities' to span other specific collaborative dynamics in relation to industry and government, results from the well-known 'triple helix' approach (Callaert et al., 2015; Cooke, 2005; Zhao et al., 2015). This focuses on the emergence of university-industry-government interactions (Leydesdorff \& Etzkowitz, 1996), now conceived of within the RIS context (Leydesdorff \& Zawdie, 2010; Lopes, Ferreira, and Farinha, 2018). In this same context, Cooke (2005) draws attention to the regional level, criticizing what gets termed 'new regionalism' that seeks to emphasize only the importance of institutions, the involvement of industry and the microscience associated with economic and social development.

The triple helix approach thus provides a useful heuristic model for theoretically grounding empirical observations in the role of different organizations. According to several authors (Farinha et al., 2019), there are no universally applicable models for regional knowledge-based development. A combination of components, interactions and functions that is successful in one region is not necessarily successful, or beneficial for another. It is necessary to adapt the structure defined in the triple helix system to the regional context (Lopes, Ferreira, \& Farinha, 2018). With the development of the triple helix literature, more focused on regional development and Smart Specialisation, an additional new actor, the end user, the public and civil society becomes more relevant (Höglund \& Linton, 2017; Lew, Khan \& Cozzio, 2016).

Over recent decades, there has been a rising interest in understanding innovation and entrepreneurship practices from the perspective of regional development (Cooke \& Leydesdorff, 2005; Farinha et al., 2019). An important reflection raised by RIS involves the best means of evaluating the perceptions of interested parties as regards the appropriateness of the strategies for intelligent specialization defined with the regional framework proposed by Lopes, Ferreira, Farinha, and Raposo (2018).

\section{METHODOLOGY}

\section{Data}

We collected citations and co-citations data from the following indexes; Science Citation Index Expanded (SCIExpanded), Social Science Citation Index (SSCI) and Social Science Citation Index (A\&H CI), compiled by the Thomson/Reuters-ISI online database that contains thousands of academic publications in conjunction with bibliographic information about their authors, affiliations and citations.

The research focused upon the Web of ScienceTM Core Collection database, incorporating the articles identified without any chronological filter by the application of the search term 'regional innovation system' in either the title, the keywords or the article abstract. The WoS was selected to ensure the academic quality standards of the papers included in this sample, and also the predominance of high quality peer-reviewed journals dealing with RISrelated topics (Jones et al., 2011; Morais \& Ferreira, 2019).

The research survey took place in January 2019 and covered every article published through to the end of 2018 with the search returning 596 articles with publication dates from between 1992 (one article) and 2018 (62 articles).

\section{Methods}

As regards the statistical and analytical methods applied to study this database, the first phase incorporated the descriptive analysis of the 596 articles resulting from the search and primarily making recourse to graphic-based methods, frequency tables and descriptive measures (medians and standard deviation), with these also the methods serving to identify the most relevant journals, the co-authorship patterns and citation analysis.

In order to test for eventual patterns among the articles, we analysed the way in which the articles get jointly cited. Whenever a set of articles gets co-cited, very commonly this reflects the shared ideas among these articles and in general depicting the central themes and intellectual structures of a field of knowledge (Leydesdorff \& Vaughan, 2006). The analysis of co-citation networks derived from 
recourse to UCINET version 6.554 (Borgatti et al., 2002) and NetDraw version 2.148 (Borgatti, 2002).

This analysis made a global level approach and for each of the respective periods. This also involved the application of hierarchal cluster analysis for all of the articles incorporated into the co-citation analysis taking into account the grouping of the articles interrelated with distinct groups and correspondingly applying co-citation network analysis designed to identify such groups and with recourse to IBM SPSS software version 24.0 (IBM Corporation, New York, NY, USA).

\section{RESULTS}

\section{Descriptives}

Figure 1 presents the annual evolution in the number of articles published as well as the number of citations. The average year of publication is $2012.2 \pm 4.7$ and thus reflecting a recently emerging field of research.

\section{Core journals}

Figures 2 and 3 display the journals with the greatest number of publication and most cited studies on RIS both globally and for each one of the three periods. The analytical objective at this stage involves identifying the main sources of RIS studies and determining just which journals hold the greatest influence on the formation of this research field and its respective content on RIS.

The 596 articles were published by 199 journals with the following journals containing the most articles: European Planning Studies (92 articles), Regional Studies (31 articles) and Research Policy (25 articles).

\section{Core literature}

Table 1 contains the most frequently cited articles on RIS in both global terms and by the respective period. In the most cited article, Cooke et al. (1997) analyse, from the evolutionary economics point of view, national innovation systems in keeping with how, for conceptual and methodological reasons and especially due to issues with scale and complexity, they might improve through incorporating a subnational focus as well as the importance of the financial capacity, institutionalized learning and the productive culture to any regionally systemic innovations.

Next up, Acs et al. (2002) explore up to what point the innovation data might get substituted by other measures as an essential step towards a better and deeper understanding of the dynamics involved. In the analysis carried out by these authors, the measurement of innovation takes place through patents at the lowest levels of geographical aggregation.

Asheim and Coenen (2005) discuss different types of RIS through five empirical studies of a comparative Nordic project on small and medium sized companies and RIS before concluding that, in innovation policy terms, the regional level generally provides a justified approach, incorporated into networks of actors that recognize the importance of the core knowledge of an industry.
Muller and Zenker (2001) give an overview of the role and function of knowledge-intensive business services (KIBS) in innovation systems and their knowledge production, transformation and dissemination activities. They studied the interactions of innovation between small and medium-sized enterprises (SMEs) and KIBS. The analysis leads to the conclusion that innovation activities link SMEs and KIBS through the process of knowledge generation and diffusion.

Rodriguez-Pose and Crescenzi (2008) studied the impact of innovation on Europe's regional economic performance. They based their study on three approaches: (1) the analysis of the link between investment in $R \& D$, patents and economic growth; (2) the study of the existence and efficiency of RIS; and (3) examining the geographical diffusion of regional knowledge repercussions. They try to bridge this gap in the literature by combining $\mathrm{R} \& \mathrm{D}$ approaches, spillovers and innovation systems in one model. The authors concluded that the complex interaction between local and external research, on the one hand, with local and external socioeconomic and institutional conditions, on the other, shapes the innovation capacity of each region. They also indicate the importance of proximity for the transmission of economically productive knowledge.

Cooke (1992) studied the concept of regulation. Formerly economic regulation was seen as necessary to the cyclically and spatially variable tendencies of capitalism, allowing a competitive system of economic activity to remain in place without collapsing under the forces of its own internal centrifugal forces. Cooke concludes that interactive learning can produce evidence of very rapid institutional reactions, although there is a time lag until economic performance and business dynamism are harmonized across regions.

Ter Wal and Boschma (2009) showed that social networks are increasingly attracting attention in economic geography. Social network analysis is a promising tool for empirically investigating the structure and evolution of interorganizational interaction and knowledge flows within and between regions. The purpose of this investigation is twofold. The first objective is to clarify the untapped potential of social network analysis techniques in economic geography. The second objective is to describe how these challenges can be met by applying network analysis techniques.

Cooke (2005) aims to review and evaluate the social scientific debate on the origins and nature of innovation in modern society. It focuses on three subsets of concepts, criticism and commentary that specifically refer to subnational or RIS. A distinct view of relevance, as it focuses on the innovation role of industry-specific 'entrepreneurial universities' in relation to industry and government, is obviously the triple helix approach. A second view is that which attacks the so-called 'new regionalism' by emphasizing the importance of institutions, insertion in the sector and the micro-science of regional economic development. Cooke conclusively proposes a knowledge-based evolution 'grounded' in the multilateral trading institution. 


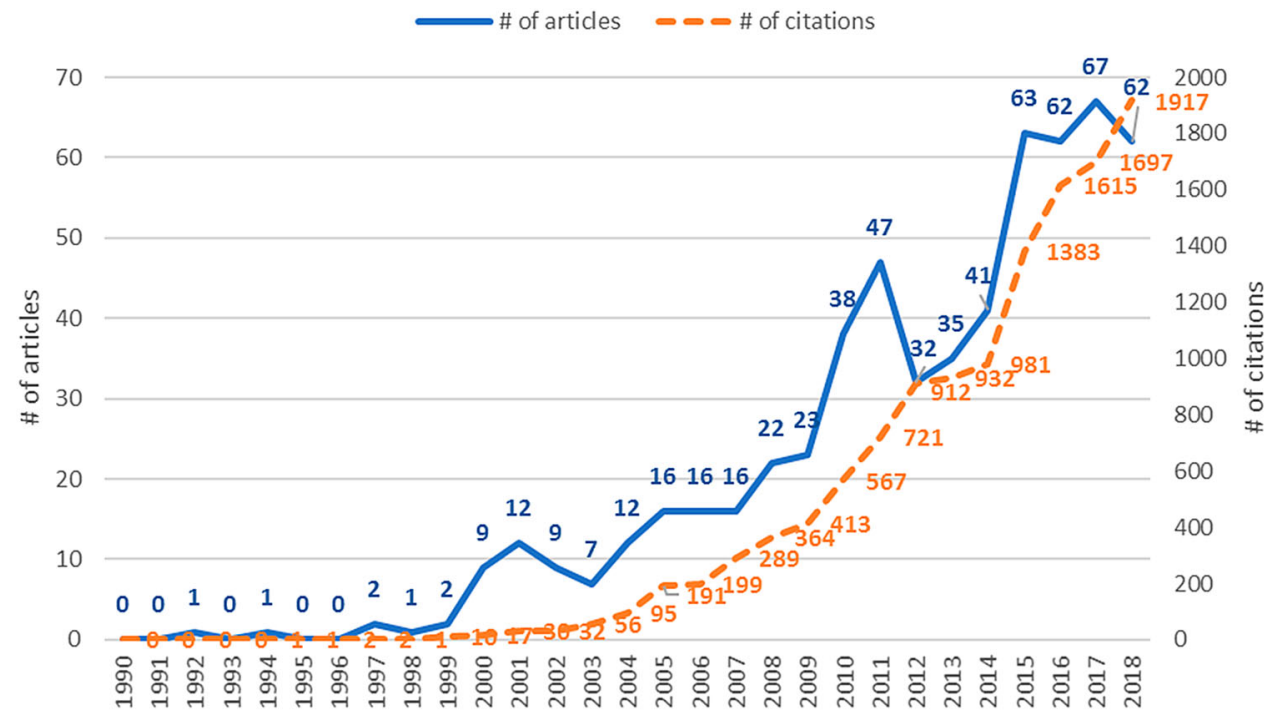

Figure 1. Evolution of the number of articles and citations.

Fritsch and Franke (2004) studied the cooperative relationships of manufacturing companies in three German regions. When applying an obstacle count data model, the differences between regions and between smaller and larger companies are analysed. The differences between regions in their propensity to cooperate are mainly due to the peculiarities of the small business sector. Spatial proximity is obviously of particular importance for horizontal cooperation and for relationships with publicly funded research institutions. The link between corporate cooperative behaviour and the performance of the RIS remains uncertain, however.

Agrawal and Cockburn (2003) examined the geographical co-location of university research and industrial $\mathrm{R} \& \mathrm{D}$ in three areas of technology. While strong evidence has been found of the co-location of these vertically connected activities, regional economies appear to vary markedly in their ability to convert academic research.

\section{Co-citation network analysis}

The articles quoted with least frequency may have had less impact on the research in this field even though there is a bias in the number of citations given that the older articles are those that are most frequently cited. In order to counter this bias, as an alternative to selecting the most cited articles, we applied the articles with the highest number of citations per year, having correspondingly retained those articles with at least five citations per year or with at least 30 citations in total. In overall terms, we deployed 64 articles out of the sample total for our co-citation analysis.

\section{Overall}

In relation to the 64 article sample as a whole, the highest co-citation frequencies feature in Table 2 that correspondingly details how the articles with the greatest number of co-citations are: (1) Cooke et al. (1997) and Asheim and Coenen (2005) with 50 co-citations; (2) Cooke et al. (1997) and Cooke (1992) with 38 co-citations; (3) Cooke et al. (1997) and Acs et al. (2002) with 31 co-citations;
(4) Acs et al. (2002) and Rodriguez-Pose and Crescenzi (2008) with 26 co-citations; and (5) Muller and Zenker (2001) and Koch and Stahlecker (2006) with 25 cocitations.

Figure 3 presents the network diagram of the core literature and clusters that provides a global image of the groups of authors approaching the respective different themes.

In a complementary fashion, Table 3 organizes the authors by groups, codifying the different approaches to the four major clusters thereby established: (1) regional knowledge systems; (2) regional institutional systems; (3) regional R\&D systems; and (4) regional network systems.

Subsequently, we set out analysis of the content of each of the correspondingly identified clusters:

\section{Cluster $1(N=17)$ : regional knowledge systems}

In this cluster, the authors dedicate their research to studying the role of the externalities of knowledge that are geographically mediated by the RIS and become an important factor in the research policy findings. While the innovation process constitutes a crucial aspect to economic growth, the problem of measuring innovation has yet to be fully resolved. Thus, the economics of knowledge would seem to pose problematic issues for formerly industrial regions given that the impediments and restructuring remove the assets necessary for innovation in their geographies as well as to policies seeking to stimulate the economies. A central problem inherent to this analysis stems from the measuring of new and economically useful knowledge. Determining up to what point innovation data are susceptible for replacement by other means of measurement incorporates an essential dimension to better understanding the dynamics involved. Analysis of the importance of the different types of RIS should take place within the context of a real knowledge base for various industries in the economy given that the innovation processes of companies get deeply shaped and fashioned by their respective specific knowledge base. 


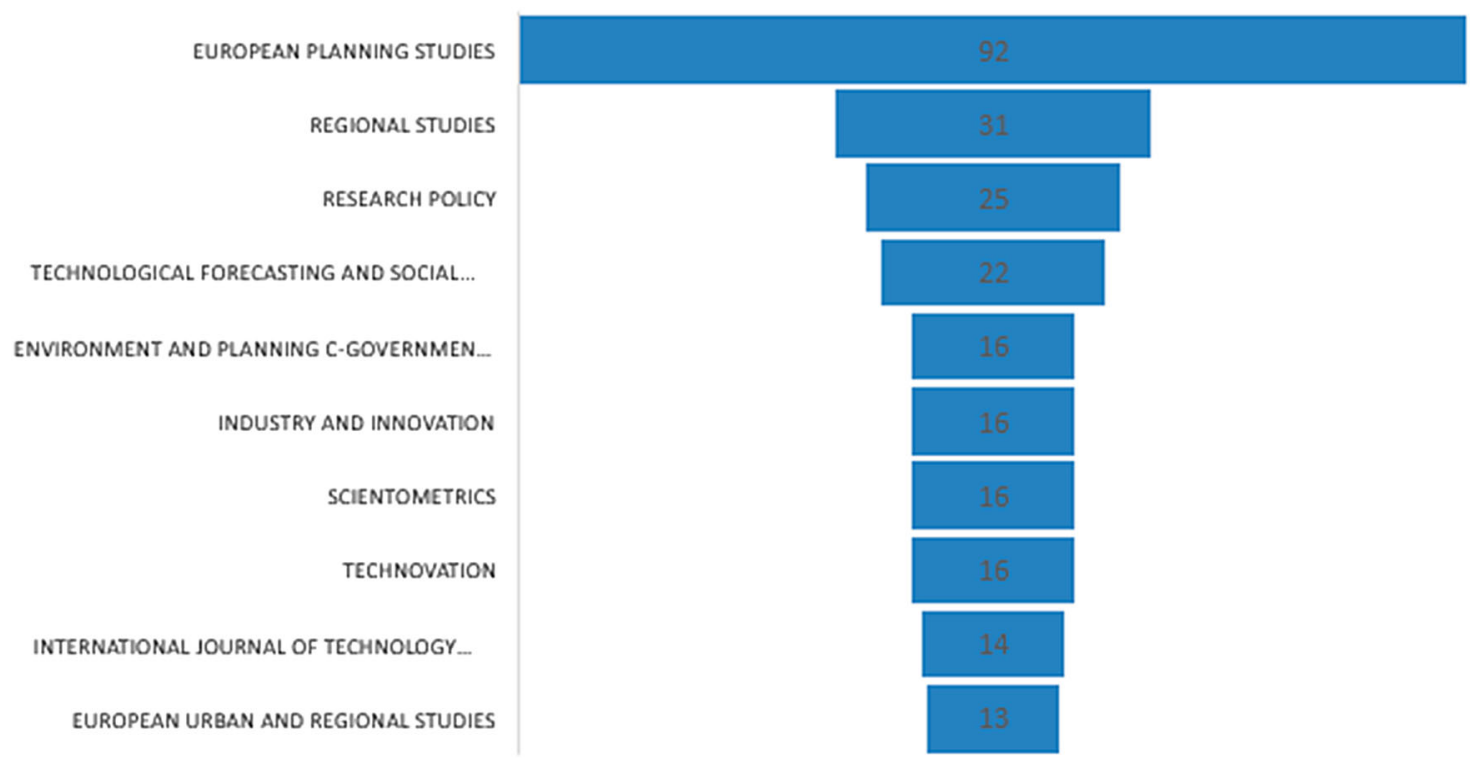

Figure 2. Top 10 journals with the most articles.

\section{Cluster $2(N=15)$ : regional institutional systems}

The authors present in this cluster conclude that RIS do not constitute a unidimensional concept. Despite their agreement with arguments around how RIS act as important determinants to economic development, the analytical findings point to how the role of regional innovative capacities does not deserve overemphasizing. Economic development firstly depends on the national contexts. Hence, there are corresponding attempts to discuss alternative means of measuring the efficiency of RIS based on the knowledge production functional concept. The spillovers from the private sector, as well as from universities and other public research institutions, generate a positive effect on the efficiency of the $\mathrm{R} \& \mathrm{D}$ undertaken by the private sector. In particular, the intensity of the interactions ongoing between public and private sector R\&D serve to boost their efficiency. Regions dominated by major establishments tend to be less efficient than regions with smaller scale institutions. The conceptual discussion around innovation systems also emphasizes the importance of these interactions between actors, institutions and the various components making up the diverse policies enacted to support technology-based economic development includes long and prominent debates about questions interrelated with national, regional, international and sectoral systems.

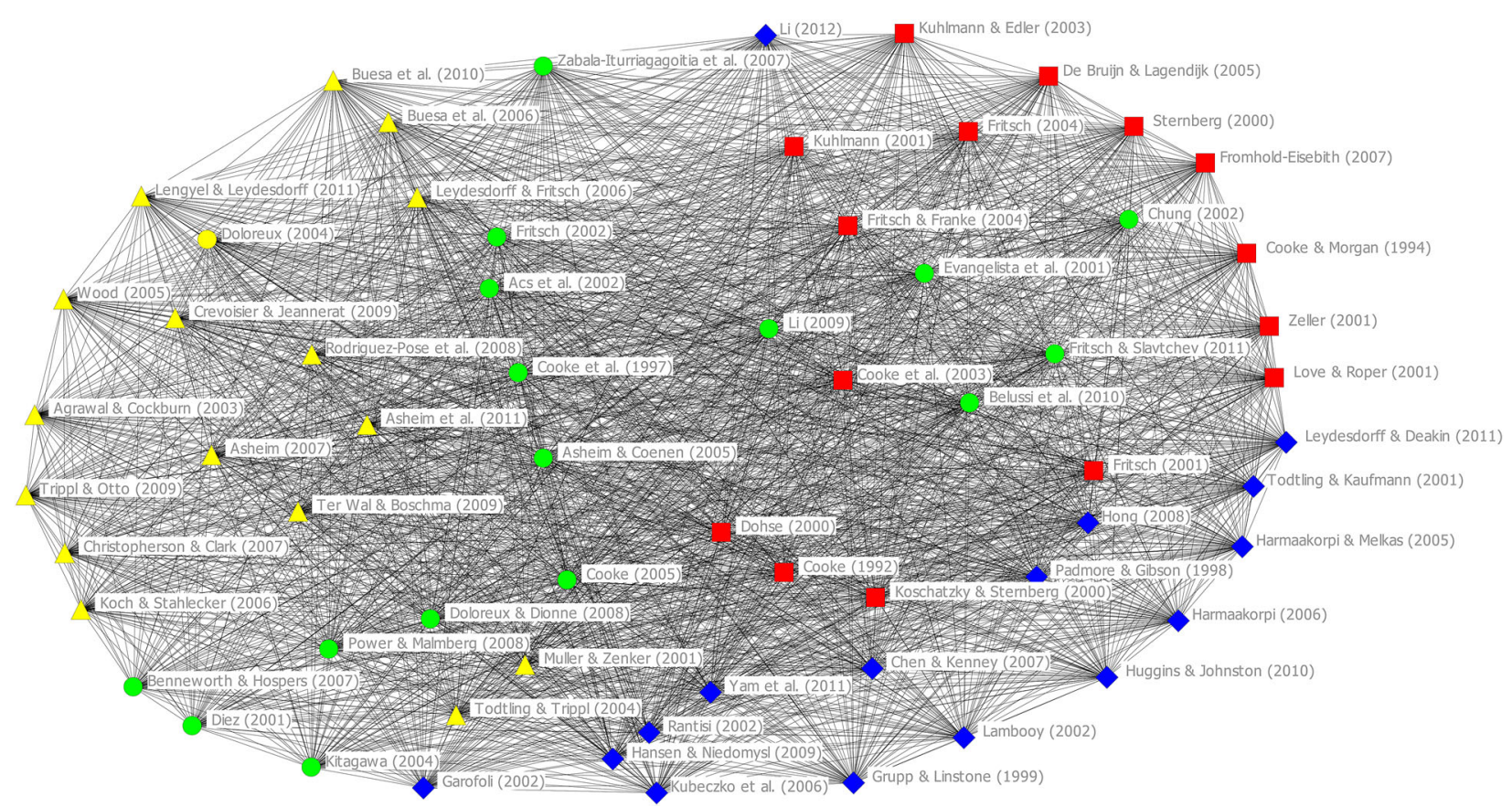

Figure 3. Network diagram of the core literature and cluster. 
Table 1. Core literature about the 'regional innovation system' (with the number of citations).

\begin{tabular}{|c|c|c|}
\hline Reference & Citations & Topics covered \\
\hline Cooke et al. (1997) & 862 & $\begin{array}{l}\text { - Analysis of national innovation systems } \\
\text { - Subnational focus and the importance of the financial capacity, institutionalized } \\
\text { learning and the productive culture to any regionally systemic innovations }\end{array}$ \\
\hline Acs et al. (2002) & 601 & $\begin{array}{l}\text { - Measurement of innovation through patents at the lowest levels of geographical } \\
\text { aggregation }\end{array}$ \\
\hline Asheim and Coenen (2005) & 569 & $\begin{array}{l}\text { - Discuss different types of regional innovation systems (RIS) } \\
\text { - Concluding that the regional innovation level generally provides a justified } \\
\text { approach, incorporated into networks of actors that recognize the importance of } \\
\text { the core knowledge of an industry }\end{array}$ \\
\hline Muller and Zenker (2001) & 386 & $\begin{array}{l}\text { - Role and function of knowledge-intensive business services (KIBS) in innovation } \\
\text { systems and their knowledge production, transformation and dissemination } \\
\text { activities } \\
\text { - Innovation activities link small and medium-sized enterprise (SME) and KIBS through } \\
\text { the process of knowledge generation and diffusion }\end{array}$ \\
\hline $\begin{array}{l}\text { Rodriguez-Pose and } \\
\text { Crescenzi (2008) }\end{array}$ & 251 & $\begin{array}{l}\text { - Impact of innovation on Europe's regional economic performance } \\
\text { - Complex interaction between local and external research, with local and external } \\
\text { socioeconomic and institutional conditions, shapes the innovation capacity of each } \\
\text { region } \\
\text { - Importance of proximity for the transmission of economically productive knowledge }\end{array}$ \\
\hline Cooke (1992) & 217 & $\begin{array}{l}\text { - Concept of regulation } \\
\text { - Interactive learning can produce evidence of very rapid institutional reactions }\end{array}$ \\
\hline $\begin{array}{l}\text { Ter Wal and Boschma } \\
\text { (2009) }\end{array}$ & 212 & $\begin{array}{l}\text { - Social networks are increasingly attracting attention in economic geography } \\
\text { - Potential of social network analysis techniques in economic geography and how } \\
\text { these challenges can be met by applying network analysis techniques }\end{array}$ \\
\hline Cooke (2005) & 197 & $\begin{array}{l}\text { - Evaluate the social scientific debate on the origins and nature of innovation in } \\
\text { - Triple helix approach: innovation role of industry-specific 'entrepreneurial } \\
\text { universities' in relation to industry and government } \\
\text { - Proposal of a knowledge-based evolution 'grounded' in the multilateral trading } \\
\text { institution }\end{array}$ \\
\hline Fritsch and Franke (2004) & 170 & $\begin{array}{l}\text { - Cooperative relationships of manufacturing companies in three German regions } \\
\text { - Differences between regions in their propensity to cooperate and the peculiarities of } \\
\text { the small business sector } \\
\text { - Spatial proximity is important for horizontal cooperation and for relationships with } \\
\text { - } \text { publicly funded research institutions } \\
\text { - Link between corporate cooperative behaviour and performance of the RIS }\end{array}$ \\
\hline $\begin{array}{l}\text { Agrawal and Cockburn } \\
\text { (2003) }\end{array}$ & 136 & $\begin{array}{l}\text { - Geographical co-location of university research and industrial research and } \\
\text { development (R\&D) in three areas of technology } \\
\text { - Co-location vertical connected activities, regional economies appear to vary } \\
\text { markedly in their ability to convert academic research }\end{array}$ \\
\hline
\end{tabular}

Cluster $3(N=17)$ : regional R\&D systems

It is extremely important to verify the relationship between the geographical co-locations of university research centres and industrial $\mathrm{R} \& \mathrm{D}$ facilities. While there is strong evidence that the co-location of these activities vertically interconnect, regional economies would seem to vary sharply in their capacities to convert local academic research into local commercial innovation. This has focused particular attention on changes in the role of learning regions in the globalized knowledge economy.

Analysis of clusters has attracted considerable interest in the most recent decades. The articulations of clusters in 
Table 2. Top 10 co-citations in terms of frequency.

\begin{tabular}{llc}
\hline Citation 1 & \multicolumn{1}{c}{ Citation 2 } & $\begin{array}{c}\text { Co- } \\
\text { citations }\end{array}$ \\
\hline Cooke et al. (1997) & $\begin{array}{l}\text { Asheim and Coenen } \\
\text { (2005) }\end{array}$ & 50 \\
Cooke et al. (1997) & Cooke (1992) & 38 \\
Cooke et al. (1997) & Acs et al. (2002) & 31 \\
Acs et al. (2002) & $\begin{array}{l}\text { Rodriguez-Pose and } \\
\text { Crescenzi (2008) }\end{array}$ & 26 \\
Muller and Zenker & Koch and Stahlecker \\
(2001) & (2006) & 25 \\
Cooke et al. (1997) & Rodriguez-Pose and & 24 \\
Asheim and Coenen & Crescenzi (2008) & \\
(2005) & Cooke (1992) & 21 \\
Acs et al. (2002) & Li (2009) & 19 \\
Acs et al. (2002) & Fritsch and Franke & 18 \\
Acs et al. (2002) & (2004) & 17 \\
\hline
\end{tabular}

complex networks and innovation systems - generally known as RIS - are in particular subject to association with the delivery of greater innovation and growth. Despite the rising economic and political relevance of clusters, there has been a shortfall of research systematically studying if this association with other factors is also able to boost innovation and economic growth. Regional growth through innovation in Europe fundamentally stems from the presence of a favourable socioeconomic environment and, in particular, the existence of a pool of well-trained and educated workers. This viewpoint defends the importance of the presence of clusters to regional growth.

Cluster $4(N=16)$ : regional network systems

The RIS concept emerged as an important framework for evaluating innovation performance levels. Hence, there is particular importance in studying the relationship between the RIS and company innovation systems in accordance with the core premise that companies that make best usage of the information sources available in their RIS will display the tendency to strengthen their capacities for technological innovation. The different innovation capacities of any firm arise out of the main components of their innovation systems.

This perspective also maintains the importance of studying the characteristics and the nature of the networks companies adopt to access knowledge and facilitate innovation. Company size plays a role in the patterns of its knowledge network. Hence, the dynamic interactions ongoing in networks prove an important source of innovation. Globally, the companies that invest most in the development of their inter-firm knowledge networks alongside other external knowledge networks return higher levels of innovation. Thus, the interconnection between the environment of a dynamic network of companies and innovation supplies an
Table 3. Article clusters based on the co-citation matrix.

\begin{tabular}{lc}
\hline Cluster 1: Regional & Cluster 3: Regional \\
knowledge systems & research and development \\
(R\&D) systems
\end{tabular}

Acs et al. (2002)

Asheim and Coenen (2005)

Agrawal and Cockburn

Belussi et al. (2010)

(2003)

Benneworth and Hospers

Asheim (2007)

(2007)

Chung (2002)

Cooke (2005)

Cooke et al. (1997)

Diez (2001)

Doloreux and Dionne (2008)

Evangelista et al. (2001)

Asheim et al. (2011)

Buesa et al. (2010)

Buesa et al. (2006)

Christopherson and Clark

(2007)

Crevoisier and Jeannerat

(2009)

Fritsch and Slavtchev (2011)

Doloreux (2004)

Fritsch (2002)

Kitagawa (2004)

Koch and Stahlecker (2006)

Lengyel and Leydesdorff

(2011)

Li (2009)

Power and Malmberg (2008)

Zabala-Iturriagagoitia et al.

(2007)

\section{Cluster 2: Regional institutional systems}

Cooke and Morgan (1994)

Cooke (1992)

Cooke et al. (2003)

De Bruijn and Lagendijk (2005)

Dohse (2000)

Fritsch and Franke (2004)

Fritsch (2001)

Fritsch (2004)

Fromhold-Eisebith (2007)

Koschatzky and Sternberg

(2000)

Leydesdorff and Fritsch

(2006)

Muller and Zenker (2001)

Rodriguez-Pose and Crescenzi (2008)

Ter Wal and Boschma (2009)

Todtling and Trippl (2004)

Trippl and Otto (2009)

Wood (2005)

\section{Cluster 4: Regional network systems}

Chen and Kenney (2007)

Garofoli (2002)

Grupp and Linstone (1999)

Hansen and Niedomysl

(2009)

Harmaakorpi and Melkas

(2005)

Kuhlmann and Edler (2003)

Kuhlmann (2001)

Harmaakorpi (2006)

Hong (2008)

Love and Roper (2001)

Sternberg (2000)

Zeller (2001)
Huggins and Johnston (2010)

Kubeczko et al. (2006)

Lambooy (2002)

Leydesdorff and Deakin

(2011)

Li (2012)

Padmore and Gibson (1998)

Rantisi (2002)

Todtling and Kaufmann

(2001)

Yam et al. (2011) 
Table 4. TCCM systematization.

\begin{tabular}{|c|c|}
\hline ry & $\begin{array}{l}\text { Which theories hold greatest relevance to the regional innovation systems (RIS) study? } \\
\text { - Should new theories be developed? } \\
\text { - What subjects, in addition to those related to the business sciences are also important to RIS (knowledge } \\
\text { spillovers theory, resource based view or network theory)? } \\
\text { - Which RIS holds the potential in terms of conceptual contributions to develop a broader reaching } \\
\text { literature? } \\
\text { - How might we interrelate the structure, the organization, the strategy and RIS? }\end{array}$ \\
\hline C: Context & $\begin{array}{l}\text { What are the similarities and differences in the various regions and their RIS? } \\
\text { - What are the similarities and differences in RIS? } \\
\text { - What factors explain these differences? } \\
\text { - What importance do informal relationships hold to the success or non-success of regions? } \\
\text { - In what way might the context drive changes in the adoption of different constructs of RIS? }\end{array}$ \\
\hline C: Characteristics & $\begin{array}{l}\text { What is the role-played by resources and capacities in defining RIS? } \\
\text { - Which factors measure the RIS - with what results at the institutional, organizational and individual levels? } \\
\text { - How do institutional logics interrelate with RIS? }\end{array}$ \\
\hline hodology & $\begin{array}{l}\text { How are we able to significantly measure RIS? } \\
\text { - How might we measure the impact of the utilization or otherwise of RIS? } \\
\text { - Do the different components of RIS require different methodologies? } \\
\text { - How might we combine various methods to explore RIS on the different levels of analysis? } \\
\text { - How might we develop large scale databases for measuring RIS? } \\
\text { - Might we apply existing methods or do we need innovative methods and drawing upon other fields to } \\
\text { effectively explain RIS? }\end{array}$ \\
\hline
\end{tabular}

alternative thesis to that defending the advantages of network stability.

\section{Research agenda}

We may report that there is a range of studies dedicated to analyzing the various factors that enable and assist RIS. The Edquist (1997) and Lundvall (1992) approaches served as an impetus for the exploitation of RIS (Cooke et al., 1997). In addition to agglomeration and competitiveness, innovation is one of the most important aspects behind economic growth at the present age of knowledge (Stough, 2003).

Thus, we would propose future recourse to the theory of knowledge spillovers, the resource-based vision or network theory so that answers may address core research questions on both the learning regions and their respective region performance standards.

Hence, and following the structure of the aforementioned review studies, we propose a future research agenda from the TCCM framework (Paul \& Rosado-Serrano, 2019) which contains the following four components: theory $(\mathrm{T})$, context $(\mathrm{C})$, characteristics and methodology $(\mathrm{M})$. Table 4 systematically sets out the TCCM framework components applied in our study.

\section{CONCLUSIONS, IMPLICATIONS AND FUTURE RESEARCH AGENDA}

Innovation emerges from its respective specific social, cultural, economic and political environment and displays a systemic character. Innovation systems thus contain factors and relations that interact with the production, dissemination and application of new economic knowledge (Edquist, 1997; Lundvall, 1992).

This approach served as a driver for the exploration of RIS (Cooke et al., 1997). Beyond clusters and competitiveness, innovation constitutes one of the most important aspects underlying economic growth within the current knowledge-based era (Stough, 2003). Porter and Stern (2001) defend how the vitality of innovation depends on the capacity for national innovation. This capacity above all conveys the potential of each country, at the political and economic levels, to produce a flow of commercially relevant innovations.

According to Camacho and Rodríguez (2005), this field requires a combination of theories ranging from the most recent to the longest standing for studying innovation in the service sector. Indeed, innovation in this type of sector needs a perspective that reaches beyond the introduction of new products or processes. Within this framework, the greatest contribution made by our study stems precisely from the systematization and grouping of the approaches made to the study of RIS.

We correspondingly verified that within the study of RIS, there are four distinct approaches and each is interrelated to different components making up the RIS characteristics that they seek to study: knowledge, institutions, $\mathrm{R} \& \mathrm{D}$ and networks. 
According to the knowledge focused regional approach, the problem with measuring innovation has yet to be fully resolved. The measuring of new economically valuable knowledge still remains a concern with a particular emphasis on the traditionally industrialized regions.

At the institutional level, the research conclusions indicate that economic development first and foremost depends on the prevailing national context. The discussion of alternative measures to achieve efficiency in RIS centred on the question if the concept of the functional production of knowledge should represent the priority.

Furthermore, the intensity of the ongoing interactions between $R \& D$ in the public and private sectors drives a rise in the prevailing levels of efficiency. Within this framework, the conclusions furthermore find that regions dominated by the presence of large establishments tend to be less efficient than regions with smaller scale institution that appear to be more agile in the definition of support policies for technologically based economic development. From the $\mathrm{R} \& \mathrm{D}$ perspective, the research results point to the presence of clusters holding important consequences for regional growth.

The capacity to convert local academic research into local commercial innovation is a determining factor to the competitiveness of learning regions in the globalized knowledge economy. In terms of regional network systems, the network dynamics provide an important source of innovation with the size of companies playing an important role in the patterns returned by their knowledge networks even while the presence of inter-company knowledge networks and other external knowledge networks with strong connections to innovation, ensure the advantages of network stability and regional progress.

Based on the broad field of study that constitutes the systemic approaches to studying RIS, we may target our analysis on these four distinct fields in the belief that this shall contribute to deepening the literature, generating knowledge on this field while also serving as the basis for scientific reflection in terms of defining regional innovation and development policies. Our study reinforces the theories of Shearmur (2010) and Hassink and Klaerding (2012), as new RIS are thought of for the territory as a delimited territorial plan, but also as spaces of opportunity centred on the exploration of resources and capabilities.

\section{DISCLOSURE STATEMENT}

No potential conflict of interest was reported by the authors.

\section{FUNDING}

The Portuguese Foundation for Science and Technology [grants and NECE- UIDB/04630/2020) provided support for this study.

\section{ORCID}

Cristina Fernandes (1) http://orcid.org/0000-0001-8560-0758

Luis Farinha (10) http://orcid.org/0000-0003-1705-5000

João Ferreira (1) http://orcid.org/0000-0002-5928-2474

Björn Asheim @ http://orcid.org/0000-0001-8681-0132

\section{REFERENCES}

Acs, Z. J., Anselin, L., \& Varga, A. (2002). Patents and innovation counts as measures of regional production of new knowledge. Research Policy, 31(7), 1069-1085. https://doi.org/10.1016/ S0048-7333(01)00184-6

Agrawal, A., \& Cockburn, I. (2003). The anchor tenant hypothesis: Exploring the role of large, local, R\&D-intensive firms in regional innovation systems. International Journal of Industrial Organization, 21(9), 1227-1253. https://doi.org/10.1016/ S0167-7187(03)00081-X

Andersson, G. (2013). Rethinking regional innovation. Systemic Practice and Action Research, 26(1), 99-110. https://doi.org/10. 1007/s11213-012-9265-5

Asheim, B. T. (2007). Differentiated knowledge bases and varieties of regional innovation systems. Innovation: European Journal of Social Science Research, 20(3), 223-241. https://doi.org/10.1080/ 13511610701722846

Asheim, B. T., \& Coenen, L. (2005). Knowledge bases and regional innovation systems: Comparing Nordic clusters. Research Policy, 34(8), 1173-1190. https://doi.org/10.1016/j.respol.2005.03.013

Asheim, B. T., \& Gertler, M. (2005). The geography of innovation: Regional innovation systems. In J. Fagerberg, D. Mowery, \& R. Nelson (Eds.), The Oxford handbook of innovation (pp. 291-317). Oxford University Press.

Asheim, B. T., Isaksen, A., \& Trippl, M. (2019). Advanced introduction to regional innovation systems. Edward Elgar.

Asheim, B. T., Smith, H. L., \& Oughton, C. (2011). Regional innovation systems: Theory, empirics and policy. Regional Studies, 45 (7, SI), 875-891. https://doi.org/10.1080/00343404.2011. 596701

Audretsch, D. B., \& Lehmann, E. E. (2005). Does the knowledge spillover theory of entrepreneurship hold for regions? Research Policy, 34(8), 1191-1202. https://doi.org/10.1016/j.respol.2005. 03.012

Belussi, F., Sammarra, A., \& Sedita, S. R. (2010). Learning at the boundaries in an 'open regional innovation system': A focus on firms' innovation strategies in the Emilia Romagna life science industry. Research Policy, 39(6), 710-721. https://doi.org/10. 1016/j.respol.2010.01.014

Benneworth, P., \& Hospers, G.-J. (2007). The new economic geography of old industrial regions: Universities as global-local pipelines. Environment and Planning C: Government and Policy, 25(6), 779-802. https://doi.org/10.1068/c0620

Borgatti, S. P. (2002). NetDraw: Graph visualization software. Analytic Technologies.

Borgatti, S. P., Everett, M. G., \& Freeman, L. C. (2002). Ucinet for Windows: Software for social network analysis. Analytic Technologies.

Buesa, M., Heijs, J., \& Baumert, T. (2010). The determinants of regional innovation in Europe: A combined factorial and regression knowledge production function approach. Research Policy, 39(6), 722-735. https://doi.org/10.1016/j.respol.2010. 02.016

Buesa, M., Heijs, J., Pellitero, M. M., \& Baumert, T. (2006). Regional systems of innovation and the knowledge production function: The Spanish case. Technovation, 26(4), 463-472. https://doi.org/10.1016/j.technovation.2004.11.007 
Callaert, J., Landoni, P., Van Looy, B., \& Verganti, R. (2015). Scientific yield from collaboration with industry: The relevance of researchers' strategic approaches. Research Policy, 44(4), 990998. https://doi.org/10.1016/j.respol.2015.02.003

Camacho, J., \& Rodríguez, M. (2005). How innovative are services? An empirical analysis for Spain. Service Industries Journal, 25(2), 253-271. https://doi.org/10.1080/0264206042000305448

Chen, K., \& Kenney, M. (2007). Universities/research institutes and regional innovation systems: The cases of Beijing and Shenzhen. World Development, 35(6), 1056-1074. https://doi.org/10.1016/ j.worlddev.2006.05.013

Christopherson, S., \& Clark, J. (2007). Power in firm networks: What it means for regional innovation systems. Regional Studies, 41(9), 1223-1236. https://doi.org/10.1080/00343400701543330

Chung, S. (2002). Building a national innovation system through regional innovation systems. Technovation, 22(8), 485-491. https://doi.org/10.1016/S0166-4972(01)00035-9

Cooke, P. (1992). Regional innovation systems: Competitive regulation in the new Europe. Geoforum; Journal of Physical, Human, and Regional Geosciences, 23(3), 365-382. https://doi.org/10. 1016/0016-7185(92)90048-9

Cooke, P. (2005). Regionally asymmetric knowledge capabilities and open innovation exploring 'globalisation 2' - A new model of industry organisation. Research Policy, 34(8), 1128-1149. https://doi.org/10.1016/j.respol.2004.12.005

Cooke, P., \& Leydesdorff, L. (2005). Regional development in the knowledge-based economy: The construction of advantage. Journal of Technology Transfer, 31(1), 5-15. doi:10.1007/ s10961-005-5009-3

Cooke, P., \& Morgan, K. (1994). The regional innovation system in Baden-Wurttemberg. International Journal of Technology Management, 9(3-4), 394-429. doi:10.1504/IJTM.1994.025582

Cooke, P., Roper, S., \& Wylie, P. (2003). 'The golden thread of innovation' and Northern Ireland's evolving regional innovation system. Regional Studies, 37(4), 365-379. https://doi.org/10. 1080/0034340032000074406

Cooke, P., Uranga, M. G., \& Etxebarria, G. (1997). Regional innovation systems: Institutional and organisational dimensions. Research Policy, 26(4-5), 475-491. https://doi.org/10.1016/ S0048-7333(97)00025-5

Crevoisier, O., \& Jeannerat, H. (2009). Territorial knowledge dynamics: From the proximity paradigm to multi-location milieus. European Planning Studies, 17(8), 1223-1241. https://doi. org/10.1080/09654310902978231

De Bruijn, P., \& Lagendijk, A. (2005). Regional innovation systems in the Lisbon Strategy. European Planning Studies, 13(8), 11531172. https://doi.org/10.1080/09654310500336519

D'Este, P., \& Patel, P. (2007). University-industry linkages in the UK: What are the factors underlying the variety of interactions with industry? Research Policy, 36(9), 1295-1313. https://doi. org/10.1016/j.respol.2007.05.002

Diez, M. A. (2001). The evaluation of regional innovation and cluster policies: Towards a participatory approach. European Planning Studies, 9(7), 907-923. https://doi.org/10.1080/ 09654310120079832

Dohse, D. (2000). Technology policy and the regions - The case of the BioRegio contest. Research Policy, 29(9), 1111-1133. https://doi.org/10.1016/S0048-7333(99)00077-3

Doloreux, D. (2002). What we should know about regional systems of innovation. Technology in Society: An International Journal, 24, 243-263. doi.org/10.1016/S0160-791X(02)00007-6

Doloreux, D. (2004). Regional innovation systems in Canada: A comparative study. Regional Studies, 38(5), 479-492. https:// doi.org/10.1080/0143116042000229267

Doloreux, D., \& Dionne, S. (2008). Is regional innovation system development possible in peripheral regions? Some evidence from the case of La Pocatiere, Canada. Entrepreneurship and
Regional Development, 20(3), 259-283. https://doi.org/10.1080/ 08985620701795525

Edquist, C. (1997). Systems of innovation approaches - Their emergence and characteristics. In C. Edquist (Ed.), Systems of innovation: Technologies, institutions and organizations (pp. 1-35). Pinter.

Eickelpasch, A., \& Fritsch, M. (2005). Contests for cooperation - A new approach in German innovation policy. Research Policy, 34 (8), 1269-1282. https://doi.org/10.1016/j.respol.2005.02.009

Etzkowitz, H., \& Leydesdorff, L. (2000). The dynamics of innovation: From national systems and 'Mode 2' to a triple helix of university-industry-government relations. Research Policy, 29(2), 109-123. doi:10.1016/s0048-7333(99)00055-4

Evangelista, R., Iammarino, S., Mastrostefano, V., \& Silvani, A. (2001). Measuring the regional dimension of innovation. Lessons from the Italian Innovation Survey. Technovation, 21 (11), 733-745. https://doi.org/10.1016/S0166-4972(00)00084-5

Farinha, L., Faria, J., \& Ferreira, J. (2019). Editorial: Special issue on triple helix dynamics for innovation and regional growth. Global Business and Economics Review, 21(3/4), 267-277. https://www. inderscience. $\mathrm{com} / \mathrm{mobile} /$ inauthors $/ \mathrm{cfp}$. php?id=3778

Fritsch, M. (2001). Co-operation in regional innovation systems. Regional Studies, 35(4), 297-307. https://doi.org/10.1080/ 00343400124434

Fritsch, M. (2002). Measuring the quality of regional innovation systems: A knowledge production function approach. International Regional Science Review, 25(1), 86-101. https://doi.org/10. 1177/016001702762039394

Fritsch, M. (2004). Cooperation and the efficiency of regional R\&D activities. Cambridge Journal of Economics, 28(6), 829-846. https://doi.org/10.1093/cje/beh039

Fritsch, M., \& Franke, G. (2004). Innovation, regional knowledge spillovers and R\&D cooperation. Research Policy, 33(2), 245255. https://doi.org/10.1016/S0048-7333(03)00123-9

Fritsch, M., \& Slavtchev, V. (2011). Determinants of the efficiency of regional innovation systems. Regional Studies, 45(7, SI), 905-918. https://doi.org/10.1080/00343400802251494

Fromhold-Eisebith, M. (2007). Bridging scales in innovation policies: How to link regional, national and international innovation systems. European Planning Studies, 15(2), 217-233. https://doi. org $/ 10.1080 / 09654310601078754$

Garofoli, G. (2002). Local development in Europe - Theoretical models and international comparisons. European Urban and Regional Studies, 9(3), 225-239. https://doi.org/10.1177/0967642002009003035

Grupp, H., \& Linstone, H. A. (1999). National technology foresight activities around the globe - Resurrection and new paradigms. Technological Forecasting and Social Change, 60(1), 85-94. https://doi.org/10.1016/S0040-1625(98)00039-0

Hansen, H. K., \& Niedomysl, T. (2009). Migration of the creative class: Evidence from Sweden. Journal of Economic Geography, 9 (2), 191-206. https://doi.org/10.1093/jeg/lbn046

Harmaakorpi, V. (2006). Regional development platform method (RDPM) as a tool regional innovation policy. European Planning Studies, 14(8), 1085-1104. https://doi.org/10.1080/ 09654310600852399

Harmaakorpi, V., \& Melkas, H. (2005). Knowledge management in regional innovation networks: The case of Lahti, Finland. European Planning Studies, 13(5), 641-659. https://doi.org/10. 1080/09654310500139277

Hassink, R., \& Klaerding, C. (2012). The end of the learning region as we knew it; towards learning in space. Regional Studies, 46(8), 1055-1066. https://doi.org/10.1080/00343404. 2012.705823

Hawkins, D. T. (1977). Unconventional uses of on-line information retrieval systems: On-line bibliometric studies. Journal of the American Society for Information Science, 28(1), 13-18. https:// doi.org/10.1002/asi.4630280103 
Höglund, L., \& Linton, G. (2017). Smart Specialization in regional innovation systems: A quadruple helix perspective. RED Management, 48(1), 60-72. doi:10.1111/radm.12306.

Hong, W. (2008). Decline of the center: The decentralizing process of knowledge transfer of Chinese universities from 1985 to 2004. Research Policy, 37(4), 580-595. https://doi.org/10.1016/j.respol. 2007.12.008

Huggins, R., \& Johnston, A. (2010). Knowledge flow and inter-firm networks: The influence of network resources, spatial proximity and firm size. Entrepreneurship and Regional Development, 22 (5), 457-484. https://doi.org/10.1080/08985620903171350

Jones, M. V., Coviello, N., \& Tang, Y. K. (2011). International entrepreneurship research (1989-2009): A domain ontology and thematic analysis. Journal of Business Venturing, 26(6), 632659. https://doi.org/10.1016/j.jbusvent.2011.04.001

Kitagawa, F. (2004). Universities and regional advantage: Higher education and innovation policies in English regions. European Planning Studies, 12(6), 835-852. https://doi.org/10.1080/ 0965431042000251882

Koch, A., \& Stahlecker, T. (2006). Regional innovation systems and the foundation of knowledge intensive business services. A comparative study in Bremen, Munich, and Stuttgart, Germany. European Planning Studies, 14(2), 123-146. https://doi.org/10. 1080/09654310500417830

Koschatzky, K., \& Sternberg, R. (2000). R\&D cooperation in innovation systems - Some lessons from the European Regional Innovation Survey (ERIS). European Planning Studies, 8(4), 487-501. https://doi.org/10.1080/713666415

Kubeczko, K., Rametsteiner, E., \&Weiss, G. (2006). The role of sectoral and regional innovation systems in supporting innovations in forestry. Forest Policy and Economics, 8(7), 704-715. https:// doi.org/10.1016/j.forpol.2005.06.011

Kuhlmann, S. (2001). Future governance of innovation policy in Europe - Three scenarios. Research Policy, 30(6, SI), 953-976. https://doi.org/10.1016/S0048-7333(00)00167-0

Kuhlmann, S., \& Edler, J. (2003). Scenarios of technology and innovation policies in Europe: Investigating future governance. Technological Forecasting and Social Change, 70(7), 619-637. https://doi.org/10.1016/S0040-1625(03)00027-1

Lambooy, J. G. (2002). Knowledge and urban economic development: An evolutionary perspective. Urban Studies, 39(5-6), 1019-1035. https://doi.org/10.1080/00420980220128435

Lee, J.-D., \& Park, C. (2006). Research and development linkages in a national innovation system: Factors affecting success and failure in Korea. Technovation, 26(9), 1045-1054. https://doi.org/10. 1016/j.technovation.2005.09.004

Lengyel, B., \& Leydesdorff, L. (2011). Regional innovation systems in Hungary: The failing synergy at the national level. Regional Studies, 45(5), 677-693. https://doi.org/10.1080/ 00343401003614274

Leuven, K. U. (2003). Entrepreneurial universities and the dynamics of academic knowledge production: A case study of basic vs. applied research in Belgium. Scientometrics, 58(2), 301-320. https://doi.org/10.1023/A:1026288611013

Lew, Y. K., Khan, Z., \& Cozzio, S. (2016). Gravitating toward the quadruple helix: International connections for the enhancement of a regional innovation system in Northeast Italy. $R E D$ Management, 48(1), 44-59. doi:10.1111/radm.12227

Leydesdorff, L., \& Deakin, M. (2011). The triple-helix model of smart cities: A neo-evolutionary perspective. Journal of Urban Technology, 18(2, SI), 53-63. https://doi.org/10.1080/ 10630732.2011.601111

Leydesdorff, L., \& Etzkowitz, H. (1996). Emergence of a triple helix of university-industry-government relations. Science and Public Policy, 23(5), 279-286. https://doi.org/10.1093/spp/23.5.279

Leydesdorff, L., \& Fritsch, M. (2006). Measuring the knowledge base of regional innovation systems in Germany in terms of a triple helix dynamics. Research Policy, 35(10), 1538-1553. https://doi.org/10.1016/j.respol.2006.09.027

Leydesdorff, L., \& Vaughan, L. (2006). Co-occurrence matrices and their applications in information science: Extending ACA to the web environment. Journal of the American Society for Information Science and Technology, 57(12), 1616-1628. https://doi.org/10. 1002/asi

Leydesdorff, L., \& Zawdie, G. (2010). The triple helix perspective of innovation systems. Technology Analysis and Strategic Management, 22(7), 789-804. https://doi.org/10.1080/ 09537325.2010 .511142

Li, X. (2009). China's regional innovation capacity in transition: An empirical approach. Research Policy, 38(2), 338-357. https://doi. org/10.1016/j.respol.2008.12.002

$\mathrm{Li}, \mathrm{X}$. (2012). Behind the recent surge of Chinese patenting: An institutional view. Research Policy, 41(1), 236-249. https://doi.org/10. 1016/j.respol.2011.07.003

Lopes, J., Ferreira, J. J., \& Farinha, L. (2018). Innovation strategies for Smart Specialisation (RIS3): Past, present and future research. Growth and Change. https://doi.org/10.1111/grow.12268

Lopes, J., Ferreira, J. J., Farinha, L., \& Raposo, M. (2018). Emerging perspectives on regional academic entrepreneurship. Higher Education Policy. https://doi.org/10.1057/s41307-018-0099-3

Love, J. H., \& Roper, S. (2001). Location and network effects on innovation success: Evidence for UK, German and Irish manufacturing plants. Research Policy, 30(4), 643-661. https://doi. org/10.1016/S0048-7333(00)00098-6

Lundvall, B. A. (1992). National systems of innovation, towards a theory of innovation and interactive learning. Pinter.

Morais, F., \& Ferreira, J. (2019). SME internationalisation process: Key issues and contributions, existing gaps and the future research agenda. European Management Journal. https://doi.org/ 10.1016/j.emj.2019.08.001

Moulaert, F., \& Sekia, F. (2003). Territorial innovation models: A critical survey. Regional Studies, 37(3), 289-302. https://doi.org/ 10.1080/0034340032000065442

Muller, E., \& Zenker, A. (2001). Business services as actors of knowledge transformation: The role of KIBS in regional and national innovation systems. Research Policy, 30(9, SI), 1501-1516. https://doi.org/10.1016/S0048-7333(01)00164-0

Mutschke, P., Mayr, P., Schaer, P., \& Sure, Y. (2011). Science models as value-added services for scholarly information systems. Scientometrics, 89(1), 349-364. https://doi.org/10.1007/s11192011-0430-x

Osareh, F. (1996). Bibliometrics, citation analysis and co-citation analysis: A review of literature: I. Libri, 46(3), 149-158. https://doi.org/10.1515/libr.1996.46.3.149

Padmore, T., \& Gibson, H. (1998). Modelling systems of innovation: II. A framework for industrial cluster analysis in regions. Research Policy, 26(6), 625-641. https://doi.org/10.1016/S0048-7333 (97)00038-3

Paul, J., \& Rosado-Serrano, A. (2019). Gradual internationalization vs born-global/international new venture models. International Marketing Review. doi:10.1108/imr-10-2018-0280

Porter, M., \& Stern, S. (2001). Innovation: Location matters. MIT Sloan Management Review, Summer, 42(4), 28-36. https:// sloanreview.mit.edu/article/innovation-location-matters/

Power, D., \& Malmberg, A. (2008). The contribution of universities to innovation and economic development: In what sense a regional problem? Cambridge Journal of Regions, Economy and Society, 1(2), 233-245. https://doi.org/10.1093/ cjres/rsn006

Predazzi, E. (2012). The third mission of the university. Rendiconti Lincei, 23(S1), 17-22. https://doi.org/10.1007/s12210-012$0182-4$

Rantisi, N. M. (2002). The local innovation system as a source of 'variety': Openness and adaptability in New York City's garment 
district. Regional Studies, 36(6), 587-602. https://doi.org/10. 1080/00343400220146740

Rinkinen, S., Oikarinen, T., \& Melkas, H. (2016). Social enterprises in regional innovation systems: A review of Finnish regional strategies. European Planning Studies, 24(4), 723-741. https:// doi.org/10.1080/09654313.2015.1108394

Rodriguez-Pose, A., \& Crescenzi, R. (2008). Research and development, spillovers, innovation systems, and the genesis of regional growth in Europe. Regional Studies, 42(1), 51-67. https://doi. org/10.1080/00343400701654186

Rondé, P., \& Hussler, C. (2005). Innovation in regions: What does really matter? Research Policy, 34(8), 1150-1172. https://doi. org/10.1016/j.respol.2005.03.011

Shearmur, R. (2010). Innovation, regions and proximity: From neoregionalism to spatial analysis. Regional Studies, 45(9), 12251243. https://doi.org/10.1080/00343404.2010.484416

Sternberg, R. (2000). Innovation networks and regional developmentEvidence from the European Regional Innovation Survey (ERIS): Theoretical concepts, methodological approach, empirical basis and introduction to the theme issue. European Planning Studies, 8(4), 389-407. https://doi.org/10.1080/713666420

Stough, R. (2003). Strategic management of places and policy. Annals of Regional Science, 37(1), 179-201. https://doi.org/10.1007/ s001680300149

Ter Wal, A. L. J., \& Boschma, R. A. (2009). Applying social network analysis in economic geography: Framing some key analytic issues. Annals of Regional Science, 43(3), 739-756. https://doi. org/10.1007/s00168-008-0258-3

Thomsom Reuters. (2008). Using bibliometrics: A guide to evaluating research performance with citation data.

Todtling, F., \& Kaufmann, A. (2001). The role of the region for innovation activities of SMEs. European Urban and Regional
Studies, 8(3), 203-215. https://doi.org/10.1177/ 096977640100800303

Todtling, F., \& Trippl, M. (2004). Like phoenix from the ashes? The renewal of clusters in old industrial areas. Urban Studies, 41(5-6), 1175-1195. https://doi.org/10.1080/ 00420980410001675788

Trippl, M., \& Otto, A. (2009). How to turn the fate of old industrial areas: A comparison of cluster-based renewal processes in Styria and the Saarland. Environment and Planning A: Economy and Space, 41(5), 1217-1233. https://doi.org/10.1068/a4129

Wood, P. (2005). A service-informed approach to regional innovation - Or adaptation? Service Industries Journal, 25(4), 429-445. https://doi.org/10.1080/02642060500092063

Yam, R. C. M., Lo, W., Tang, E. P. Y., \& Lau, A. K. W. (2011). Analysis of sources of innovation, technological innovation capabilities, and performance: An empirical study of Hong Kong manufacturing industries. Research Policy, 40(3), 391-402. https://doi.org/10.1016/j.respol.2010.10.013

Zabala-Iturriagagoitia, J. M., Voigt, P., Gutierrez-Gracia, A., \& Jimenez-Saez, F. (2007). Regional innovation systems: How to assess performance. Regional Studies, 41(5), 661-672. https:// doi.org/10.1080/00343400601120270

Zeller, C. (2001). Clustering biotech: A recipe for success? Spatial patterns of growth of biotechnology in Munich, Rhineland and Hamburg. Small Business Economics, 17(1-2), 123-141. https:// doi.org/10.1023/A:1011182624329

Zhao, S. L., Cacciolatti, L., Lee, S. H., \& Song, W. (2015). Regional collaborations and indigenous innovation capabilities in China: A multivariate method for the analysis of regional innovation systems. Technological Forecasting and Social Change, 94, 202-220. https://doi.org/10.1016/j.techfore.2014. 09.014 